Special issue of the International Conference on Computational and Experimental Science and Engineering (ICCESEN 2014)

\title{
Kinetic and Thermodynamic Behavior of Selenium on Modified Bentonite and Activated Carbon using Radiotracer Technique
}

\author{
B. TuĞrul, S. Erentürk, S. HaciyakupoĞlu, N. Karatepe, N. Altinsoy,
} N. BaydoĞAn, F. Baytaş, B. BÜyük, E. Demir And S. Gedik*

Istanbul Technical University, Energy Institute, 34469, Maslak-Istanbul, Turkey

This study was aimed to determine kinetic and thermodynamic behaviors of selenium on modified bentonite and activated carbon. Thermodynamic parameters such as enthalpy $\Delta H$, free energy change $\Delta G$ and entropy change $\Delta S$ of selenium adsorption suggested that the adsorption of Se(IV) on activated carbon and organicinorganic modified bentonite was exothermic and endothermic process, respectively. The experimental data fitted very well the pseudo-second-order kinetic model for both adsorbents.

DOI: 10.12693/APhysPolA.128.B-180

PACS: $28.90 .+\mathrm{i}$

\section{Introduction}

Selenium is an important element for humans, but it should be controlled with regard to both toxicity and deficiencies in livestock. Mining activities, fossil fuel processing, combustion, industrial, agricultural and metallurgical processes cause to increase selenium concentration in related aqueous environment. As known, activated carbon and modified bentonite can be used for safely purifying the environment. The relative importance of test parameters like solution $\mathrm{pH}$, contact time, temperature and concentration of adsorbate on adsorption performance of modified bentonite and activated carbon for selenium(IV) ion were studied in our previous studies [1-3]. In this study, kinetics and thermodynamic behavior of Se were studied in aqueous media.

\section{Materials and method}

The original selenium dioxide compound was irradiated in central irradiation tube of TRIGA Mark II nuclear reactor at Istanbul Technical University at $250 \mathrm{~kW}$ in $1 \mathrm{~h}$. The stock solution of selenium(IV) $(1780 \mathrm{mg} / \mathrm{L})$ was prepared by dissolving appropriate amounts of irradiated selenium dioxide compound $\left(\mathrm{SeO}_{2}\right.$, Fluka, 99\% purity) and used as radiotracer.

Activated carbon from lignite by physical activation and organic-inorganic modified bentonite (OIMBent) samples were prepared as given in our previous studies $[1-3]$.

Batch experiments were carried out by using radioactive selenium solution satisfying $0.05 \mathrm{~L} / \mathrm{g}$ liquid/solid ratio at different temperature and contact time. Data for kinetic and thermodynamic studies were obtained by determination of ${ }^{75} \mathrm{Se}$ radioactivity at high resolution gamma spectrometry system. In the adsorption process, the variation in thermodynamic parameters $(\Delta H, \Delta S$ and $\Delta G$ ) are very important to determine the spontaneity of adsorption process. $\Delta H, \Delta S$ and $\Delta G$ parameters

*corresponding author; e-mail: gedikso@itu.edu.tr were obtained from adsorption experiment data in the temperature range of $293-323 \mathrm{~K}$ as follows:

$$
\begin{aligned}
& K_{\mathrm{d}}=\frac{C_{\mathrm{i}}-C_{\mathrm{e}}}{C_{\mathrm{e}}} \frac{V}{m}, \quad \Delta G=-R T \ln \left(K_{\mathrm{d}}\right), \\
& \Delta G=\Delta H-T \Delta S, \quad \ln K_{\mathrm{d}}=\frac{\Delta S}{R}-\frac{\Delta H}{R T},
\end{aligned}
$$

where $K_{\mathrm{d}}$ is equilibrium constant, $C_{\mathrm{e}}$ is the equilibrium concentration of the solute, $C_{\mathrm{i}}$ is the concentration of the solute in solution at any time, $V$ is volume of the solution, $m$ is mass of the adsorbent, $T$ is temperature in $\mathrm{K}$ and $R$ is the gas constant. The values of $\Delta H$ and $\Delta S$ were obtained from the slope and intercept of the Van't Hoff plot of $\ln \left(K_{\mathrm{d}}\right)$ versus $1 / T$ [4-6].

In order to explain the mechanism of the adsorption processes, first and pseudo-second-order rate expressions were used to investigate the behavior of adsorption process of Se(IV) onto activated carbon and OIMBent. The Lagergren first-order rate expression based on solid capacity is generally expressed as follows:

$$
\log \left(q_{\mathrm{e}}-q_{\mathrm{t}}\right)=\log q_{\mathrm{e}}-\frac{k_{1} t}{2.303}
$$

where $q_{\mathrm{t}}$ and $q_{\mathrm{e}}\left(\mathrm{mg} \mathrm{g}^{-1}\right)$ are the amounts of the metal ions adsorbed at equilibrium $\left(\mathrm{mg} \mathrm{g}^{-1}\right)$ and $t(\mathrm{~min})$, respectively, and $k_{1}$ is the rate constant of the equation $\left(\mathrm{min}^{-1}\right)$. The adsorption rate constants $\left(k_{1}\right)$ can be determined experimentally by plotting of $\ln \left(q_{\mathrm{e}}-q_{\mathrm{t}}\right)$ versus $t$.

The pseudo-second kinetic model has been applied to heterogeneous systems, where the sorption mechanism is attributed to chemical sorption and the sorption capacity is proportional to the number of active sites on the sorbent. The model can be represented by the following equation:

$$
\frac{t}{q_{\mathrm{t}}}=\frac{1}{k_{2} q_{\mathrm{e}}^{2}}+\frac{t}{q_{\max }}
$$

where $k_{2}\left(\mathrm{~g} \mathrm{~mol}^{-1} \mathrm{~min}^{-1}\right)$ is the second-order rate constant, $q_{\mathrm{t}}, q_{\mathrm{e}}$ and $q_{\max }\left(\mathrm{mg} \mathrm{g}^{-1}\right)$ are the amounts of the metal ions adsorbed at equilibrium $\left(\mathrm{mg} \mathrm{g}^{-1}\right)$ and $t(\mathrm{~min})$ and maximum, respectively. The linear plot of $t / q_{\mathrm{t}}$ as a function of $t$ provided not only the rate constant $k_{2}$, but also an independent evaluation of $q_{\mathrm{e}}$. 


\section{Results and discussion}

To investigate the effect of temperature, the sorption of Se(IV) ions onto activated carbon and OIMBent was studied in the temperature range of 293-323 K. Figure 1 illustrates the effect of temperature for adsorption of $\mathrm{Se}(\mathrm{IV})$ ions on the adsorbents. The adsorption of Se(IV) on activated carbon decreased as the solution temperature increased. This downtrend can be explained by the exothermic spontaneity of the Se(IV) adsorption and by the weakening of bonds between Se(IV). The adsorption of Se(IV) on OIMBent increased with temperature. This uptrend indicates that the $\mathrm{Se}(\mathrm{IV})$ adsorption process was endothermic.

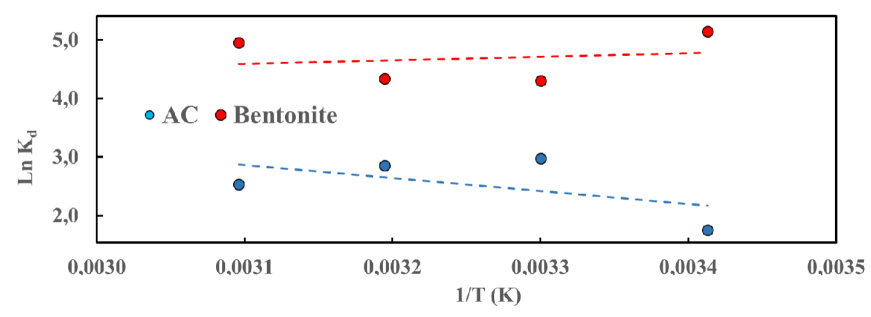

Fig. 1. Effect of temperature on the adsorption of selenium ions on activated carbon and OIMBent.

TABLE I

Thermodynamic parameters for selenium adsorption on activated carbon and OIMBent.

\begin{tabular}{c|c|c|c|c|c|c}
\hline \hline \multirow{2}{*}{$\mathrm{T}(\mathrm{K})$} & \multicolumn{3}{|c|}{ Activated Carbon } & \multicolumn{3}{c}{ OIMBent } \\
\cline { 2 - 6 } & $\Delta G$ & $\Delta H$ & $\Delta S$ & $\Delta G$ & $\Delta H$ & $\Delta S$ \\
\cline { 2 - 6 } & \multicolumn{2}{|c|}{$[\mathrm{kJ} / \mathrm{mol}]$} & {$[\mathrm{J} /(\mathrm{mol} \mathrm{K})]$} & \multicolumn{2}{c}{$\mathrm{kJ} / \mathrm{mol}]$} & {$[\mathrm{J} /(\mathrm{mol} \mathrm{K})]$} \\
\hline 293 & -42.09 & -18.40 & 80.85 & -1.62 & 5.01 & 22.65 \\
303 & -42.90 & & & -1.85 & & \\
313 & -43.70 & & & -2.08 & & \\
323 & -44.51 & & & -2.30 & & \\
\end{tabular}

TABLE II

Values of the Lagergren first-order model and pseudosecond-order model constants.

\begin{tabular}{c|c|c|c|c}
\hline \hline Adsorbent & $k_{1}[1 / \mathrm{min}]$ & $R_{1}$ & $\begin{array}{c}k_{2} \\
{[\mathrm{~g} /(\mathrm{mol} \min )]}\end{array}$ & $R_{2}$ \\
\hline $\begin{array}{c}\text { activated } \\
\text { carbon }\end{array}$ & $-1.15 \times 10^{-3}$ & 0.4716 & 0.2112 & 0.9956 \\
OIMBent & $6.91 \times 10^{-4}$ & 0.6363 & 0.0199 & 0.9943
\end{tabular}

Table I shows the calculated values of the thermodynamic parameters for the activated carbon and OIMBent. The changes in standard Gibbs free energy $(\Delta G)$ at four different temperatures were all negative for two adsorbents. The negative values in $\Delta G$ indicate that selenium adsorption on the adsorbents was spontaneous nature of the adsorption process. The decrease in $\Delta G$ values with increase of the temperature indicated that high temperature accelerated the adsorption process. The positive value in $\Delta H(5.01 \mathrm{~kJ} / \mathrm{mol})$ for OIMBent implied that the adsorption was endothermic. Conversely, the negative value in $\Delta H(-18.40 \mathrm{~kJ} / \mathrm{mol})$ for activated car- bon indicates that the adsorption process was exothermic. The adsorption is chemisorption if the value in $\Delta H$ is between 40 and $120 \mathrm{~kJ} / \mathrm{mol}$, otherwise the adsorption is physicosorption. According to this concept, those adsorption processes seem to be physicosorption. The positive value in $\Delta S$ for both the adsorbents was reflected that the selenium dispersion on surface of the adsorbents was more chaotic than that in the aqueous solution and there is an increase in the randomness in the system solid/solution interface during the adsorption process.

The kinetic experimental results were fitted to the pseudo-second kinetic model. The correlation coefficients for the pseudo-second-order kinetic model at different time were found above 0.99 (Table II). These data give perfect fit for this model for both adsorbents. Therefore, the rate-limiting step may be chemical sorption or chemisorption through sharing or exchange of electrons between sorbent and adsorbate.

\section{Conclusion}

Comparative advantages for the thermodynamic and kinetic behaviors of activated carbon and OIMBent for $\mathrm{Se}(\mathrm{IV})$ ions remediation from aqueous media were investigated. Thermodynamic parameters $\Delta H, \Delta S$ and $\Delta G$ were calculated from the adsorption data of $\mathrm{Se}(\mathrm{IV})$ ions. These parameters indicate that adsorption is endothermic and spontaneous for OIMBent and is exothermic for activated carbon. The kinetic data for both adsorbents conformed better to the pseudo-second kinetic equation which suggests that the rate-limiting step is a chemical adsorption involving valence forces through sharing or exchange of electrons between selenium ions and surface functional groups of the both adsorbents.

\section{References}

[1] A.B. Tugrul, S. Haciyakupoglu, S. Akyıl Erenturk, N. Karatepe, A.F. Baytas, N. Altinsoy, N. Baydogan, B. Buyuk, E. Demir, ' in: Impacts and Solutions to Global Warming, Eds.: I. Dincer, C.O. Colpan, F. Kadioglu, Springer, 2013, Ch. 19.

[2] A.B. Tugrul, S. Haciyakupoglu, S. Erenturk, N. Karatepe, A.F. Baytas, N. Baydogan, N. Altinsoy, B. Buyuk, E. Orucoglu, E. Demir, Z. Camtakan, M. Okka, in: Acta Phys. Pol. A 127, 1186 (2015).

[3] A.B. Tugrul, N. Karatepe, S. Haciyakupoğlu, S. Erentürk, N. Baydogan, F. Baytaş, B. Buyuk, E. Demir, in: Int. Conf. on Energy and Management, ICEM2014, Istanbul 2014, Eds.: A.N. Bilge, A.O. Toy, M.E. Günay, p. 97.

[4] S. Erenturk, S. Haciyakupoglu, E. Orucoglu, R.K. İleri, in: 17th Radiochemical Conf., Marianske Lazne (Czech Republic) 2014, Book of Abstracts.

[5] Y. Zhou, Z. Wang, Q. Zhang, X. Xi, J. Zhang, W. Yang, Desalination 307, 61 (2012).

[6] J. Romero-González, J.R. Peralta-Videa, E. Rodriguez, S.L. Ramirez, J.L. Gardea-Torresdey, J. Chem. Thermodynam. 37, 343 (2005). 